\title{
Effective engagement of male partners of adolescent girls and young women in HIV services: Implementation science research in Swaziland
}

Population Council

Follow this and additional works at: https://knowledgecommons.popcouncil.org/departments_sbsr-hiv

Part of the Demography, Population, and Ecology Commons, Family, Life Course, and Society Commons, International Public Health Commons, Medicine and Health Commons, and the Women's Health Commons How does access to this work benefit you? Let us know!

\section{Recommended Citation}

Population Council. 2017. "Effective engagement of male partners of adolescent girls and young women in HIV services: Implementation science research in Swaziland," DREAMS Activity Brief. Washington, DC: Population Council. 


\section{EFFECTIVE ENGAGEMENT OF MALE PARTNERS OF ADOLESCENT GIRLS AND YOUNG WOMEN IN HIV SERVICES \\ IMPLEMENTATION SCIENCE RESEARCH IN SWAZILAND}

HIV prevalence among adults 18-49 in Swaziland is estimated to be 29 percent-the highest in the world. ${ }^{1}$ Considering the entire population (across all ages), 31 percent of females are HIV positive compared to 20 percent of males. ${ }^{2}$ Adolescent girls and young women (AGYW) in Swaziland, as in many countries, are particularly vulnerable to HIV due to a host of reasons, including economic disadvantage and lack of powe to negotiate condom use or refuse sex with their male partners-many of whom are older and/or engage in high-risk behaviors.

Men's uptake of HIV testing and treatment falls far short of that needed to significantly decrease new infections among their generally younger female partners. While HIV testing has increased rapidly in recent years, only 54 percent of HIV-positive men in Swaziland tested and received their results in the last year (compared with 66 percent among women). And although adult antiretroviral treatment (ART) coverage is among the highest in the world at 67 percent, ${ }^{1}$ men tend to enter ART programs at a more advanced clinical stage than women and, as a consequence, have substantially higher mortality rates. ${ }^{3}$ Bolstering men's engagement in HIV services, therefore, is critical for their own health and that of their partners.

The Kingdom of Swaziland Government is responding to these challenges by strengthening and scaling up a variety of strategies to increase men's uptake of HIV services. These strategies, supported by PEPFAR and other initiatives, include expanding male-friendly HIV testing services and linkages to care, increasing awareness of these services through intensive outreach, and improving systems to link HIV-positive men to care and treatment.

The Population Council is conducting implementation research in collaboration with local partner organizations to learn more about men's relationships with AGYW and how HIV services can better engage themtwo neglected areas of research. Similar studies are being conducted in South Africa, Uganda, and Malawi. Learnings from these studies will region, as well as HIV prevention, care, and treatment efforts for AGYW and their male partners globally, particularly in this era of test and start.

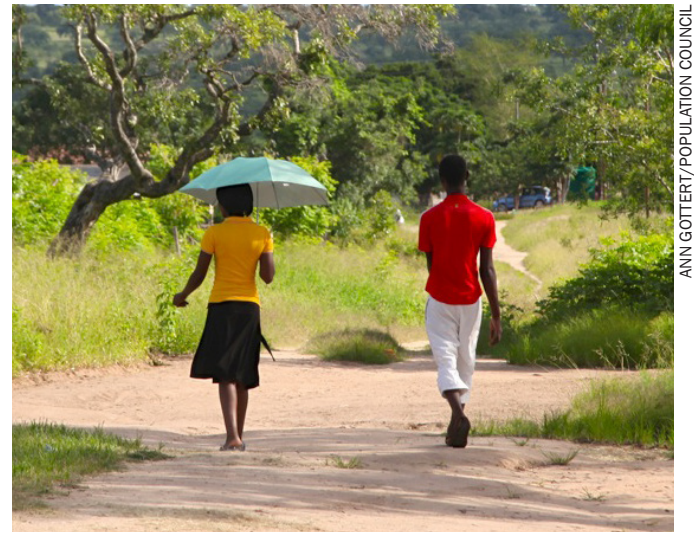

Exploring men's perspectives about their relationships with AGYW and how HIV services can better engage them will be valuable for informing ongoing HIV prevention, care, and treatment efforts.

Research Partners: Institute for Health Measurement (IHM) Southern Africa

Location: 19 districts (Tinkhundlas)

Study Duration: 2016-2018

Funder: Bill \& Melinda Gates

Foundation

For more information, contact Ann Gottert (agottert@popcouncil.org), or Patrick Shabangu (patrick@inmafrica. org). 


\section{POPULATION COUNCIL'S DREAMS IMPLEMENTATION RESEARCH}

This study is part of a portfolio of implementation science studies the Population Council is conducting, with funding from the Bill \& Melinda Gates Foundation, related to the DREAMS (Determined, Resilient, Empowered AIDS-free, Mentored, and Safe) Partnership. This Partnership aims to significantly reduce new HIV infections among AGYW in 10 countries in sub-Saharan Africa, including Swaziland. Our studies are exploring whether the intended beneficiaries-AGYW and their male partners-are being reached and retained in services, how different intervention components are being delivered to each group, and ultimately whether HIV risk among AGYW is being reduced.

\section{OUR RESEARCH}

Using mixed methods and capturing multiple perspectives, we seek to examine male partners' characteristics and perspectives and assess the successes and challenges of the intervention strategies.

We will collect qualitative data from AGYW's male partners, implementing partners, HIV service providers, and community leaders. These data will help us understand the types of relationships men have with AGYW, the dynamics within these relationships, and men's perceptions and use of HIV services. To complement these findings and to serve as the study's baseline, we will conduct secondary analysis of survey data $^{*}$ from more than 700 men (ages 20-34) and 700 AGYW (ages 15-24) recruited at "hot spot" venues across 19 districts. "Hot spots" are places where AGYW meet new sexual partners such as hotels, bars, parks, taxi stands.

We will conduct a follow-up survey one year later with approximately 1,100 men across the 19 districts to determine how effective the strategies were in reaching and retaining AGYW's male partners in HIV services.

*These data are being collected by MEASURE Evaluation.
The survey results will be supplemented with qualitative data collected from male partners, program staff, and HIV service providers to provide a richer picture of the implementation processes, successes, and challenges of male engagement strategies.

\section{RESEARCH UTILIZATION}

We will actively engage key stakeholders throughout the study, including in interpreting the findings, formulating program and policy recommendations, and supporting their adoption in Swaziland and beyond. Stakeholders in Swaziland include, among others, the Ministry of Health, the National Emergency Response Council on HIV and AIDS, the Swaziland National AIDS Program, PEPFAR, civil society groups, and implementing partners, such as $\mathrm{HC} 3$ and PSI.

\section{WHAT WILL WE LEARN?}

This innovative implementation science study will generate valuable evidence about:

- The diversity and dynamics of relationships between men and AGYW in Swaziland.

- Men's perceptions about how HIV services can best respond to their needs, and their decisionmaking about these services in the context of new test and start policies.

- The effectiveness of different strategies to reach the right men with the right services.

- Implementing partners' evolving, on-theground processes and experiences with these strategies-information that is rarely systematically documented or disseminated.

${ }^{1}$ UNAIDS. 2016. "Prevention GAP report." Geneva: UNAIDS.

${ }^{2}$ Kingdom of Swaziland and UNAIDS. 2014. "Swaziland global AIDS response progress reporting 2014.” Geneva: UNAIDS.

${ }^{3}$ Mills, E.J., N. Ford, and P. Mugyenyi. 2009. "Expanding HIV care in Africa: making men matter," The Lancet 374(9686): 275-6.
POPULATION COUNCIL

Ideas. Evidence. Impact.
The Population Council confronts critical health and development issues-from stopping the spread of HIV to improving reproductive health and ensuring that young people lead full and productive lives. Through biomedical, social science and public health research in about 50 countries, the Council works with our partners to deliver solutions that lead to more effective policies, programs, and technologies to improve lives worldwide. Established in 1952 and headquartered in New York, the Council is a nongovernmental, nonprofit organization with an international board of trustees. popcouncil.org

Suggested citation: Population Council. 2017. "Male partners of adolescent girls and young women in Swaziland: implementation science around relationship dynamics and effective engagement of men in HIV services," DREAMS Activity Brief. Washington, DC: Population Council. 